\title{
On the determination of the settling flux of cohesive sediments in a turbulent fluid
}

\author{
N. Gratiot ${ }^{1}$ \\ UR053 (Ecosystèmes Littoraux Sous Influence Amazonienne), Institut de Recherche pour le Développement, Cayenne, \\ French Guiana \\ H. Michallet \\ Laboratoire des Ecoulements Géophysiques et Industriels, Université Joseph Fourier, INPG, CNRS, Grenoble, France \\ M. Mory \\ Ecole Nationale Supérieure en Génie des Technologies Industrielles, Université de Pau et des Pays de l'Adour, Pau, France \\ Received 28 September 2004; revised 12 December 2004; accepted 11 March 2005; published 10 June 2005.
}

[1] In this paper we compare the settling flux of a cohesive sediment mixture measured in a quiescent fluid with that achieved in a turbulent flow. Experiments were performed in a mixing tank. The turbulence produced mechanically by an oscillating grid maintains a stationary, highly concentrated fluid mud layer in which the concentration is almost uniform. In this layer the turbulence decay with increasing distance from the grid is similar to that obtained in clear water. For steady conditions the settling flux of the fluid mud mixture is balanced by the upward turbulent flux, and its value can be determined from the measured depth of the fluid mud layer. At high concentrations $\left(10-200 \mathrm{~g} \mathrm{~L}^{-1}\right)$, we show that the settling flux in a turbulent fluid is much larger than estimated in a quiescent fluid (up to two orders of magnitude). Hindering effects in the settling process of cohesive sediments may thus be considerably reduced by turbulence.

Citation: Gratiot, N., H. Michallet, and M. Mory (2005), On the determination of the settling flux of cohesive sediments in a turbulent fluid, J. Geophys. Res., 110, C06004, doi:10.1029/2004JC002732.

\section{Introduction}

[2] It has been established for a long time [e.g., Migniot, 1968; Mehta, 1989] that the settling flux of cohesive sediments varies widely with the suspended sediment concentration (SSC). It is generally considered that up to a few grams per liter, flocculation of individual particles leads to an increase in the settling flux, while above $10 \sim 20 \mathrm{~g} \mathrm{~L}^{-1}$ the settling flux starts to decrease because of interparticle hindrance. This process has a major implication for the distribution of suspended sediment in natural flow. Hence the nonlinear dependence of settling flux with concentration is often considered as playing a key role in the formation and maintenance of marked stratifications in the fluid column. These so-called lutoclines are frequently observed in estuaries or in muddy coastal environments [e.g., Wolanski et al., 1988; Mehta, 1989; Kineke et al., 1996]. Conceptually, it is considered that a lutocline separates the fluid column into two distinct layers, namely the dilute suspension layer above and the fluid mud layer below [Ross and Mehta, 1989].

[3] One critical point for determining the settling of a sediment suspension concerns the measurement techniques.

\footnotetext{
${ }^{1}$ Now at Laboratoire d'étude des Transferts en Hydrologie et Environnement, IRD, UJF, INPG, CNRS, Grenoble, France.

Copyright 2005 by the American Geophysical Union. 0148-0227/05/2004JC002732\$09.00
}

The classical methods use a sample of mixed fluid mud which is left to settle in a quiescent water column. These methods neglect the contribution of turbulence in the settling. Hindering effects only are considered. It is known that turbulence shearing that occurs in the field may also lead to a modification in the overall motions and properties of flocs by their aggregation or breakage [van Leussen, 1986]. This was demonstrated experimentally by Wolanski et al. [1992], who observed a decrease by a factor of up to ten in the sediment settling flux in the presence of a very small amount of turbulence (Reynolds number of the order of 10). A grid was used to stir the suspension in their experiments. Wolanski et al. [1992] attributed the decrease in settling flux to the clogging of microchannels which usually form under quiescent conditions in the upper few centimeters of a fluid mud layer. This hindered dewatering mechanism is one of the effects induced at low turbulence levels. Floc breakage on the other hand is assumed to increase settling flux when turbulence increases, as expected in our experiments for $R e>6000$.

[4] This work aims at quantifying the effect of turbulence on the settling flux of a fluid mud suspension. The so-called grid-stirred experimental devices have been used many times in the past to examine the propagation of shear-free turbulence across density interfaces but only a few studies consider fluid mud layer formation and turbulence-sediment interaction [E and Hopfinger, 1987; Wolanski et al., 1989, 1992; Huppert et al., 1995]. In the present work, a fully 
mixed fluid mud mixture is introduced into a box within which a diffusive turbulence flow is generated by stirring with a grid. Competitive processes take place between the gravitational sediment settling flux on the one hand and the upward turbulent flux on the other, leading to an equilibrium state. In most cases, this equilibrium state is characterized by a strong stratification (lutocline) separating the upper dilute suspension layer from the lower fluid mud layer. Because the fluid mud layer is permanently mixed by the turbulent flow, we classify it as a concentrated benthic suspension (CBS) layer. The set of experiments undertaken during this work and the contributions of recent measurements [Gratiot, 2000; Mory et al., 2002] and modeling [Matsunaga et al., 1999; Michallet and Mory, 2004] have provided bases for clarifying the role of turbulence on settling flux. The turbulence is not significantly affected by the presence of sediment except in the vicinity of the lutocline. The lutocline position only depends on the sediment characteristics (density and settling velocity), the mean concentration in the CBS and the grid forcing. This result, established for noncohesive sediments of known settling velocity, is used to deduce the settling flux of cohesive sediments in turbulent flow.

[5] In section 2 of the paper we first present results concerning the dependence of sediment settling flux on concentration as measured in quiescent conditions. These data are compared with previous studies and will serve as a reference for the runs under turbulent conditions. Section 3 is devoted to a presentation of the grid-stirred setup and a description of the experimental procedures. An analysis of the experimental results obtained under turbulent conditions is presented and discussed in section 4. The results concerning the role of turbulence are addressed in the conclusion.

\section{Cohesive Sediment Settling Flux Measured in a Fluid at Rest}

[6] In the last decade, instrumentation to measure sediment settling flux has been improved considerably. One noticeable improvement is the development of video systems, which provide simultaneous measurements of floc diameter, shape, and settling velocity [Fennessy et al., 1994; Dyer and Manning, 1999]. By extracting flocs rapidly and carefully from a turbulent flow, the most recent devices have given a better understanding of the role of turbulence shearing, concentration and biology on floc aggregation and breakup; and consequently a better description of the settling velocity of individual flocs was obtained [van Leussen, 1994; Milligan and Hill, 1998; Fugate and Friedrichs, 2002; Gratiot and Manning, 2004]. Despite this improvement, video techniques are no longer suitable in fluid mud with a concentration exceeding a few grams per liter $\left(5-10 \mathrm{~g} \mathrm{~L}^{-1}\right)$. Flocs are sufficiently close together to interact and trigger many processes such as breakage, reflocculation and cloud settling effects. For high concentrations, the mean sediment settling flux is usually deduced from SSC measurements with Owen tubes or using similar techniques based on the application of mass conservation [see, e.g., Dyer et al., 1996]. In any case, these systems do not operate in turbulent flow. This limitation is the first motivation of the present study.
[7] The mud used in this study was extracted from the Gironde estuary (France). It was chemically treated with potassium permanganate to prevent organic activity and sieved at $100 \mu \mathrm{m}$. Sediment analysis performed by de Croutte et al. [1996] revealed that the sediment's median diameter was about $D_{50} \approx 12 \mu \mathrm{m}$ and the sand content (63$100 \mu \mathrm{m}$ ) was below $3 \%$. The clay fraction contained mainly illite $(35 \%)$, kaolinite $(27 \%)$, smectite $(24 \%)$ and chlorite (14\%). Between two experiments, the mud was stored in dark bottles in the laboratory. No particular care was taken concerning temperature because chemical treatment eliminated biological activity.

[8] A set of settling experiments were performed in a quiescent fluid to determine the variation in settling flux with the concentration of sediment in the suspension. The settling flux is theoretically determined from the measurement of the settling velocity of individual flocs $w_{s}(D)$ using the statistical average defined as

$$
\phi=\int_{0}^{\infty} w_{s}(D) \rho_{s} \frac{\pi D^{3}}{6 V}(1-p) n(D) d D
$$

where $n(D)$ is the number of particles of diameter $D$ in the volume $V$, and $p$ is the porosity in the floc. However, for most practical applications, (1) remains inapplicable. First, it is necessary to measure individual properties of hundreds of flocs to reach a statistically convergent value. Secondly, no measurement technique can provide all individual floc properties (in particular floc porosity) when the concentration exceeds a few grams per liter. For these reasons, the sediment settling flux is usually estimated as

$$
\phi=W_{S} C,
$$

where $W_{S}$ and $C$ are the mean settling velocity of individual flocs and the mean SSC, respectively. During the first stage of this work, four tests were performed in the range [0.2 5.0] $\mathrm{g} \mathrm{L}^{-1}$. They showed that (2) underestimates the settling flux by about $10-20 \%$ as compared with the application of (1). The results presented in this paper display variations in settling flux with concentration which cover several orders of magnitude. Therefore the underestimation of $\phi$ resulting from the application of (2) for low SSC values as compared with (1) remains negligible.

[9] Up to $C \approx 5 \mathrm{~g} \mathrm{~L}^{-1}$, the sediment settling flux was deduced using the INSSEV video system [Fennessy et al., 1994]. Fluid mud was mixed for half an hour in a gridstirred device (described in the next section) and syringe samples were taken and introduced in a settling column for video recording. Each record gives a measurement of the individual floc diameter $D_{f}$ and settling velocity $w_{s}$ as presented in Figure 1. The settling flux $\phi$, is then calculated from equation (2), $W_{S}$ being the mean settling velocity computed for all individual flocs measured. For high SSC $\left(C \geq 30 \mathrm{~g} \mathrm{~L}^{-1}\right)$, the Kynch [1952] method was employed to estimate $W_{S}$ and the mean suspended sediment concentration $C$. We do not intend to discuss the instrumental methods more deeply. We only recall here that the Kynch method underestimates the settling velocity, because it actually measures the minimum settling velocity of particles in the suspension. 


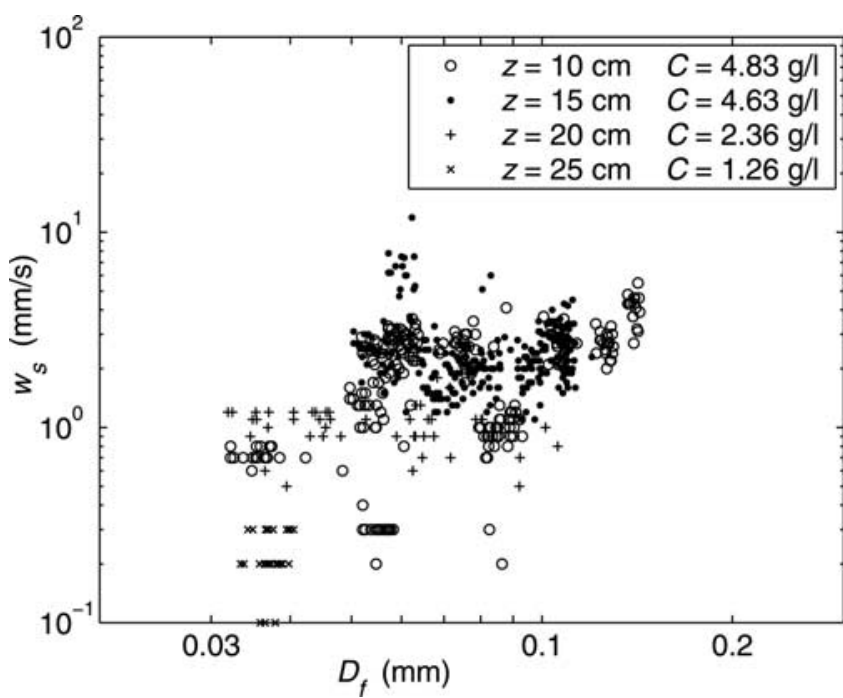

Figure 1. Settling velocities versus floc diameter measured with the INSSEV video system (run 6 of Table 1). The flocs were extracted at four different levels in the gridstirred experiment: $z=10$ and $15 \mathrm{~cm}$ are in the CBS layer; $z=20 \mathrm{~cm}$ is just below the lutocline; and $z=25 \mathrm{~cm}$ is in the dilute suspension layer.

[10] Figure 2a shows the variation for the whole concentration range of the settling flux $\phi=W_{s} C$ measured in a quiescent fluid. Different behaviors are noticed for low concentration $\left(C \leq 5 \mathrm{~g} \mathrm{~L}^{-1}\right)$ and for high concentration $\left(\mathrm{C}>30 \mathrm{~g} \mathrm{~L}^{-1}\right)$. The video measurements performed for low SSC provide interesting information on the floc properties of the mud used during this study (Figure 2a, circles). The mean floc diameter does not vary very much with SSC. It increases slightly from $D_{f} \approx 55 \mu \mathrm{m}$ when $C \approx 0.2 \mathrm{~g} \mathrm{~L}^{-1}$ to $D_{f} \approx 82 \mu \mathrm{m}$ when $C \approx 5.0 \mathrm{~g} \mathrm{~L}^{-1}$. These estimates are significantly higher than the measured median sediment diameter $D_{50} \approx 12 \mu \mathrm{m}$. Therefore it is clear that primary particles were aggregated to form compacted and solidly stuck structures. Up to SSC values of $5 \mathrm{~g} \mathrm{~L}^{-1}$, these structures are stable and do not vary significantly with concentration (weak flocculation and/or breakage). This indicates that the hydrodynamic forcing has a limited effect on individual floc properties. The data fit the empirical power law

$$
\phi=0.0023 C^{1.1}
$$

and are in good agreement with the settling flux estimated using the Stokes free-fall velocity of a $80 \mu \mathrm{m}$ diameter spherical particle of density $1800 \mathrm{~kg} \mathrm{~m}^{-3}$ (dashed line in Figure 2a).

[11] The results obtained in the hindered settling range $\left(C>30 \mathrm{~g} \mathrm{~L}^{-1}\right.$, solid lines in Figure 2a) were analyzed in terms of the model developed by Toorman [1992, 1999]. From experimental evidence, the latter suggested the existence of two distinct modes of settling, namely sedimentation and consolidation. Sedimentation occurs when flocs settle in an individual manner whereas consolidation begins when flocs become space filling. A network structure, called a gel, then develops and an effective stress builds up. For these two modes, a combined expression of the settling flux reads

$$
\phi=w_{s} C=C w_{s_{1}} \exp \left(-\frac{C}{C_{1}}\right) F_{t}+C w_{s 2}\left(1-\frac{C}{C_{2}}\right)^{3}\left(1-F_{t}\right)
$$

with

$$
F_{t}=\exp \left(-\left(\frac{C}{C_{\mathrm{gel}}}\right)^{n}\right)
$$

The first term in the right hand side of (4a) describes the sedimentation regime at low concentration. A characteristic settling velocity $w_{s 1}$ and a concentration parameter $C_{1}$ are
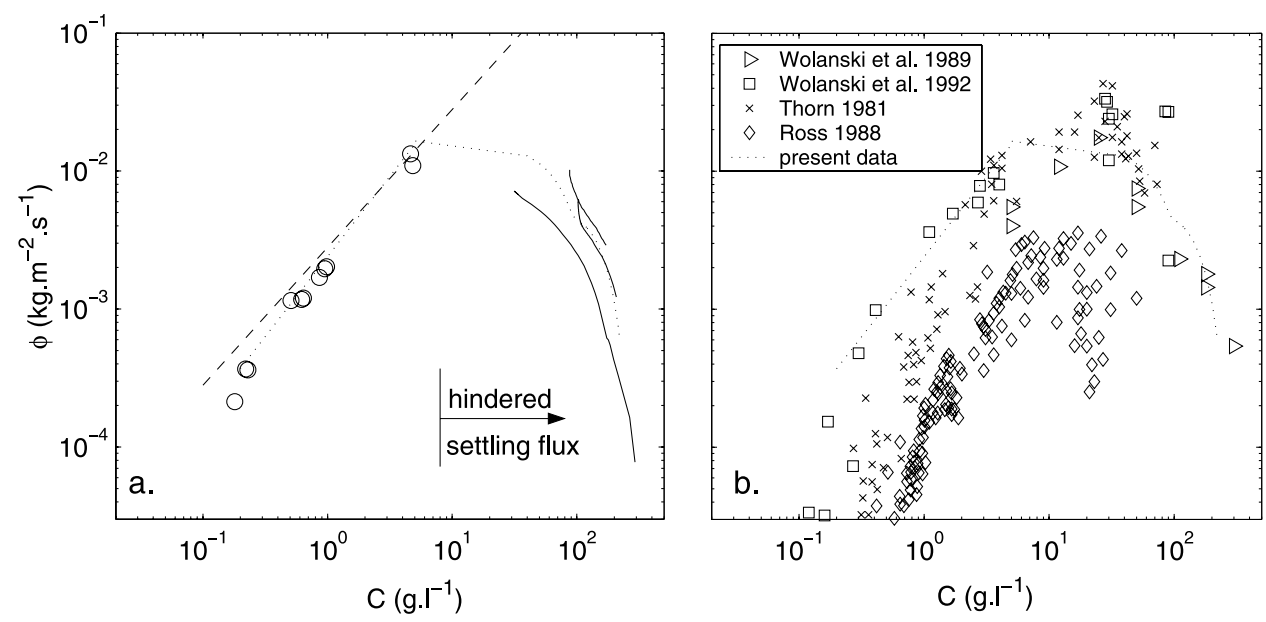

Figure 2. Settling flux in a fluid at rest versus concentration. (a) Present study: measurement using INSSEV (circles) and the Kynch [1952] method in a settling column (solid lines). The dotted line is a plot of equation (4). The dashed line is the settling flux computed using the Stokes free-fall velocity. (b) Comparison of sediment settling flux variations versus suspended sediment concentration measured in various field and laboratory studies. 


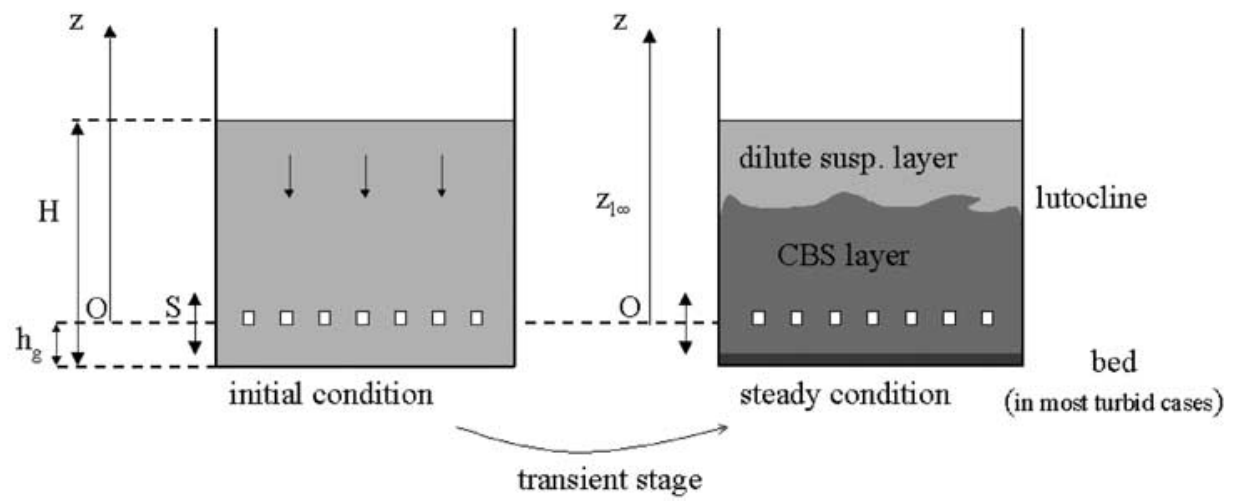

Figure 3. Grid-stirred experimental procedure.

introduced. The second term in (4a) accounts for the consolidation regime at high concentration, introducing another characteristic settling velocity $w_{s 2} . C_{2}$ is the concentration in the maximum compacted mud bed. The function $F_{t}$ describes the transition between the two regimes. It occurs at the gel point given by the gel concentration $C_{\mathrm{gel}}$. The parameters in (4a) were adjusted to the experimental data shown in Figure 2a. Equation (4a) is plotted in Figures $2 \mathrm{a}$ and $2 \mathrm{~b}$ as the dotted line for the following values of the parameters:

$$
\begin{gathered}
C_{1} \approx 30 \mathrm{~g} \mathrm{~L}^{-1}, \\
w_{s 1}=1.2 \times 10^{-3} \mathrm{~m} \mathrm{~s}^{-1}, \\
w_{s 2}=1.5 \times 10^{-4} \mathrm{~m} \mathrm{~s}^{-1}, \\
C_{2}=300 \mathrm{~g} \mathrm{~L}^{-1}, \\
n=13, \\
C_{\text {gel }} \approx 95 \mathrm{~g} \mathrm{~L}^{-1} .
\end{gathered}
$$

This set of parameters is consistent with values reported in the literature [see Winterwerp, 2002]. This empirical law does not fit perfectly with the experiments, but the important point is that all our trials led to a very similar gel concentration: $C_{\text {gel }} \approx 95 \mathrm{~g} \mathrm{~L}^{-1}$. This estimation of the concentration at which consolidation occurs in quiescent conditions will be again discussed in section 4 .

[12] The change in settling flux with SSC deduced from our experiments is compared in Figure $2 \mathrm{~b}$ with previous field and experimental data. In Wolanski et al.'s [1989, 1992] experiments, a commercially available kaolinite was introduced into a tank and actively mixed by stirring with a grid. Settling flux measurements started as soon as the grid was stopped. These works deserve particular attention here because they were conducted with an instrumental setup very similar to ours. The data of Thorn [1982] and Ross [1988] were collected from field surveys. All data plotted on Figure $2 \mathrm{~b}$ show the same dependence between settling flux and SSC. There is a clear increase in the sediment settling flux for SSC up to a few grams per liter, a threshold level in the range $7 \sim 30 \mathrm{~g} \mathrm{~L}^{-1}$, and a clear hindering beyond. Measurements conducted with inorganic mud [Wolanski et al., 1989, 1992] (also our data) present higher settling flux values than the field data. The differences are most probably due to the different types of mud, i.e., mean floc diameter and density, which vary strongly with the mud composition and the presence of organic content [Dyer et al., 1996; Manning and Dyer, 1999; Milligan and Hill, 1998; Gratiot and Manning, 2004]. However, since our main concern is the role of turbulence on settling, we do not intend to discuss biological effects more deeply. Besides, $\mathrm{McCool}$ and Parsons [2004] studied the effect of turbulent mixing in convective plumes on the settling of fine-grained sediments and found similar results with natural and inorganic sediments. The important point here is that Figure $2 b$, as well as many other data reported in the literature, demonstrate a clear hindering effect in quiescent water for highly concentrated fluid mud layers.

\section{Description of the Grid-Stirred Experiment}

[13] The interaction of fluid mud mixtures with turbulence flow was investigated in a grid-stirred experiment. Turbulence is created inside the tank by a diffusive mechanism. A sketch of our setup is shown in Figure 3. The box is a square Perspex tank $53 \mathrm{~cm}$ wide and $90 \mathrm{~cm}$ high. For all the experiments, the water depth is $H=40 \mathrm{~cm}$. The grid is fixed horizontally on a vertical steel bar that serves as a guide for stirring. The mean grid position is located at $h_{g}=$ $5 \mathrm{~cm}$ above the bottom of the tank. It oscillates at a controlled frequency $F(3,4$, or $6 \mathrm{~Hz})$ with a stroke (twice the amplitude) $S=4.5 \mathrm{~cm}$. The grid is made of seven square bars in the two horizontal directions. The thickness of the square bars is $m=1.5 \mathrm{~cm}$ with a mesh size $M=7.5 \mathrm{~cm}$. This geometry agrees with the standard ratio $M / m=5$. It corresponds to a grid porosity of nearly $65 \%$, which has been proved to be the most efficient for reducing secondary flows [Hopfinger and Toly, 1976].

[14] Starting from clear water continuously stirred by the oscillating grid, a given amount of sediment is loaded from above in the mixed water. For each grid oscillation condition a saturation concentration can be determined. Turbulence can only maintain a limited quantity of sediment in suspension over the entire fluid layer. When the averaged concentration exceeds the saturation concentration, a downward settling flux occurs (Figure 3a). This is a transient stage. An equilibrium state is finally obtained after some time when the upward turbulent flux $\langle w c\rangle$ counterbalances the downward sediment settling flux $\phi=W_{s} C$. In our setup 
Table 1. Experimental Parameters and Equilibrium State Conditions ${ }^{\mathrm{a}}$

\begin{tabular}{|c|c|c|c|c|c|c|}
\hline Experiment & Run & Symbol & $F, \mathrm{~Hz}$ & $C_{\mathrm{CBS}}, \mathrm{g} \mathrm{L}^{-1}$ & $z_{\ell \infty}, \mathrm{cm}$ & $R i_{o}$ \\
\hline 1 & 1 & cross & 3 & clear water & $\ldots$ & 0 \\
\hline 2 & 2 & open circle & 6 & clear water & $\ldots$ & 0 \\
\hline 3 & 3 & open circle & 3 & 202 & 9.5 & 6.0 \\
\hline 4 & 4 & filled circle & 3 & 149 & 9.0 & 4.4 \\
\hline 5 & 5 & cross & 6 & 51 & 15.0 & 0.38 \\
\hline 6 & 6 & open square & 4 & 3.8 & 22.5 & 0.063 \\
\hline 7 & 7 & left-facing triangle & 4 & 1.4 & 27.5 & 0.023 \\
\hline 8 & 8 & diamond & 4 & 0.9 & free surface & 0.015 \\
\hline 9 & 9 & asterisk & 4 & 4.7 & 21.5 & 0.078 \\
\hline 10 & 10 & asterisk & 4 & 4.9 & 18 & 0.081 \\
\hline 11 & 11 & asterisk & 4 & 11.6 & 17 & 0.19 \\
\hline 12 & 12 & cross & 4 & 0.9 & 33 & 0.015 \\
\hline 12 & 13 & cross & 4 & 1.6 & 27 & 0.027 \\
\hline 12 & 14 & cross & 4 & 1.5 & 25 & 0.025 \\
\hline 12 & 15 & cross & 4 & 2.4 & 21 & 0.040 \\
\hline 13 & 16 & triangle & 4 & 3.2 & 19.5 & 0.053 \\
\hline 13 & 17 & triangle & 4 & 5.3 & 18 & 0.088 \\
\hline 13 & 18 & triangle & 4 & 8.8 & 16.5 & 0.15 \\
\hline 13 & 19 & triangle & 4 & 22 & 15.5 & 0.37 \\
\hline 13 & 20 & triangle & 4 & 45 & 13.5 & 0.75 \\
\hline 13 & 21 & triangle & 4 & 81 & 11.8 & 1.35 \\
\hline 13 & 22 & triangle & 4 & 129 & 11.5 & 2.14 \\
\hline 13 & 23 & inverted triangle & 4 & 133 & 11.8 & 2.21 \\
\hline 14 & 24 & inverted triangle & 4 & 112 & 11.8 & 1.86 \\
\hline 14 & 25 & inverted triangle & 4 & 66 & 12.5 & 1.10 \\
\hline 14 & 26 & inverted triangle & 4 & 43 & 13 & 0.71 \\
\hline 14 & 27 & inverted triangle & 4 & 29 & 14.3 & 0.48 \\
\hline 14 & 28 & inverted triangle & 4 & 17 & 15.3 & 0.28 \\
\hline 14 & 29 & inverted triangle & 4 & 10.7 & 16 & 0.18 \\
\hline 14 & 30 & inverted triangle & 4 & 6.4 & 17 & 0.11 \\
\hline 14 & 31 & inverted triangle & 4 & 6.3 & 17.5 & 0.10 \\
\hline 14 & 32 & inverted triangle & 4 & 5.3 & 18 & 0.088 \\
\hline 14 & 33 & inverted triangle & 4 & 3.5 & 19 & 0.058 \\
\hline
\end{tabular}

${ }^{\mathrm{a}}$ Corresponding values of the Richardson number (equation $(9 \mathrm{c})$ ) are indicated.

the saturation concentration is about $1 \sim 2 \mathrm{~g} \mathrm{~L}^{-1}$ for a grid oscillation frequency of $4 \mathrm{~Hz}$ [Mory et al., 2002]. This value increases for higher grid oscillation frequencies. As observed in previous grid-stirred experiments [ $E$ and Hopfinger, 1987; Wolanski et al., 1989; Huppert et al., 1995; Gratiot, 2000], a two layer system is established in the equilibrium state (Figure $3 \mathrm{~b}$ ) when the concentration is higher than the saturation concentration. A marked stratification (called the lutocline) separates the dilute suspension layer from the well-mixed fluid mud layer. The final lutocline position is denoted $z_{\ell \infty}$. A deposited bed can also be observed for the most turbid cases. The concentration in the fluid mud layer, denoted $C_{\mathrm{CBS}}$, is almost uniform.

[15] Fourteen experiments were conducted with varying suspended sediment load and grid oscillation conditions, which are given in Table 1. The experiments covered a wide range of situations from nonstratified to highly stratified steady conditions. A unique sediment loading was achieved in experiments 1 to 11 , whereas subsequent sediment loading operations were performed during experiments 12 to 14 . During experiments 12 and 13, once a steady state was reached, a quantity of sediment was added and a new steady state was obtained. During experiment 14, a quantity of concentrated fluid mud was extracted from the bottom of the tank when a steady state was established and replaced by clear water to reach a new steady state. Each equilibrium condition is labeled as a run in Table 1. For each run, the equilibrium state was reached asymptotically after a period of as long as several hours and was characterized by determining the mean sediment concentration $C_{\mathrm{CBS}}$ and by estimating the mean lutocline elevation $z_{\ell \infty}$ above the mean grid position. $C_{\mathrm{CBS}}$ is obtained from sampling or using an optical backscatter system (OBS). For sampling, a measured volume $(\approx 100 \mathrm{~mL})$ of fluid mud is extracted by pumping fluid during about $5-10 \mathrm{~s}$ from the middle of the CBS layer. With an eddy turnover timescale of about a second, the pumping period is assumed to be sufficiently long to get unbiased $C_{\mathrm{CBS}}$ estimates. After decantation and drying, the solid fraction was obtained by weighing. OBS data were recorded over $30 \mathrm{~s}$ at a frequency of $10 \mathrm{~Hz}$. During the first runs, sampling and OBS methods were conducted simultaneously to check their mutual agreement. In each case, the precision was better than $5 \%$ (with a minimum resolution of $50 \mathrm{mg} \mathrm{L}^{-1}$ ).

[16] In runs 1 to 8 , characterization of the equilibrium state was completed by measurement of the vertical profiles of the suspended sediment concentration $C(z)$ and the turbulent kinetic energy $k(z)$. These measurements are particularly interesting for examining the nature of the turbulence-sediment interaction within the CBS layer and across the lutocline. Estimation of $k$ required the development of an acoustic Doppler velocimeter (ADV) capable of measuring turbulent velocity in highly concentrated fluid mud layers [Gratiot et al., 2000]. The sensor was fixed on a vertical bar and was moved up (or down) gradually to acquire vertical profiles. The mounted system provided measurements of the one-component horizontal fluctuating velocity at different locations in front of the probe. The rms 

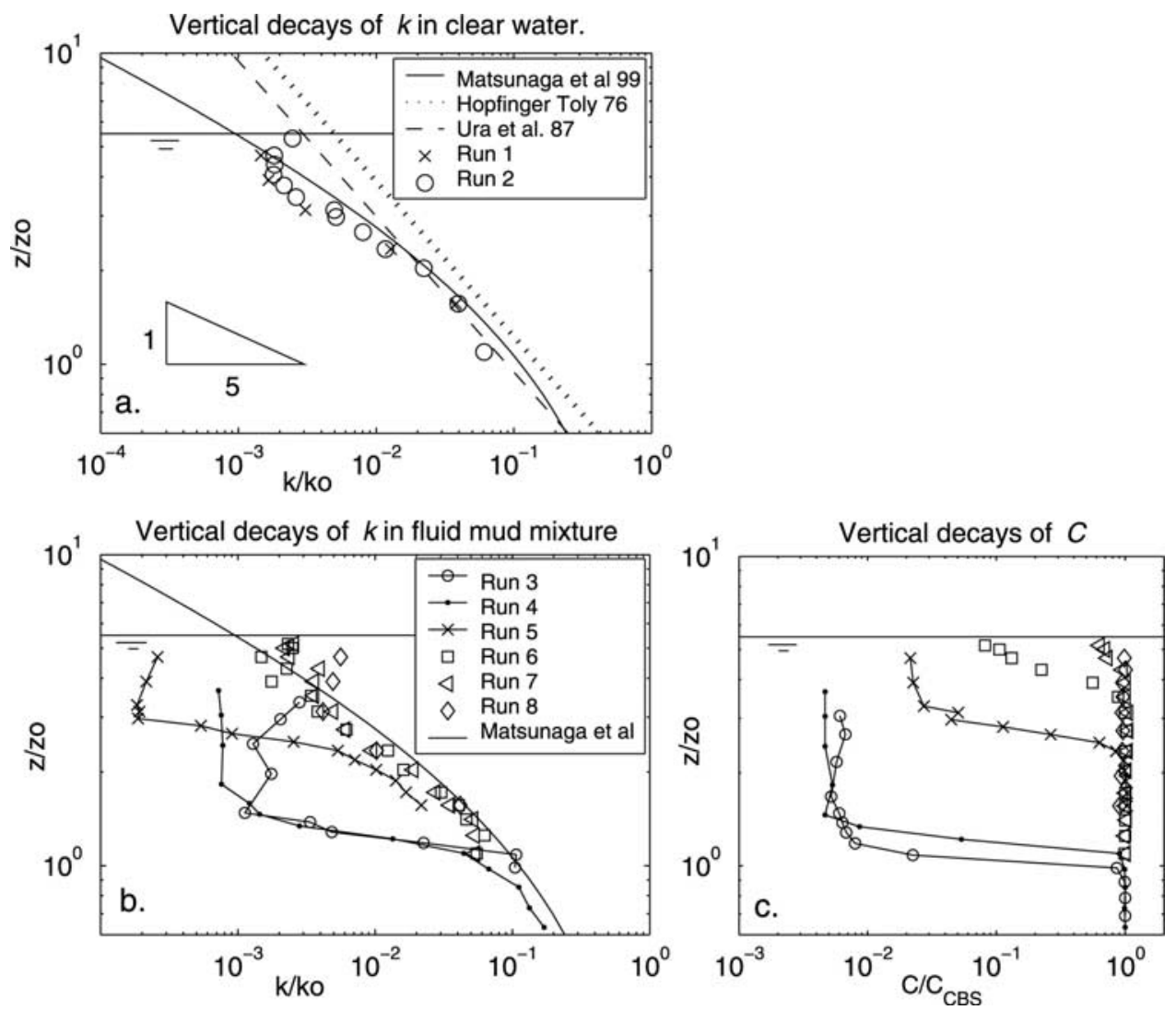

Figure 4. Dimensionless vertical profiles of turbulent kinetic energy $k(z)$ in clear water experiments (4a) and in fluid mud experiments (4b) and dimensionless vertical profiles of the mean sediment concentration $C(z)(4 c)$. Symbols and experimental parameters are given in Table 1.

velocity $u$ was calculated by arithmetically averaging all the time series acquired simultaneously at the same elevation above the grid. Each value of the mean turbulent kinetic energy $k(z)$ was deduced from about 4000 turbulent velocity measurements. As we were not able to produce simultaneous measurements of the vertical and horizontal turbulent velocity, the turbulent kinetic energy was deduced from measurements of $u$ assuming that $k=1 / 2\left(2 u^{2}+w^{2}\right) \approx 3 / 2 u^{2}$.

\section{Turbulence-Sediment Interaction}

\subsection{Vertical Profiles of $k(z)$ and $C(z)$}

[17] Vertical profiles of the suspended sediment concentration and of the turbulent kinetic energy are presented in Figures $4 c$ and $4 b$, respectively, for different experiments whose conditions are given in Table 1. The stratification of fluid mud is clearly visible in Figure 4c. We may classify the experiments into highly stratified conditions (runs $3-5$ ), moderately stratified conditions (run 6) and well mixed conditions (runs 7-8). For each experiment, turbulence in the CBS layer remains sufficiently high to mix the sediment fully up to the lutocline and the concentration is nearly constant:

$$
C(z) \approx C_{\mathrm{CBS}}=\text { constant for } z<z_{\ell \infty} .
$$

$C$ is damped abruptly through the lutocline and stabilizes to less than 1 gram per liter in the dilute suspension layer. For highly stratified conditions (runs $3-5$ ), the gradient of $C$ occurs within a layer as little as $2-3 \mathrm{~cm}$ in thickness. This thickness is caused mainly by the variations in concentration due to the displacements of the lutocline. In moderately stratified conditions (run 6), the thickness increases up to ten centimeters and mixing is more active. The lutocline is more diffuse and highly convoluted. In run 8 , no lutocline is visually observed. The turbulent kinetic energy is here sufficiently high to maintain sediment in suspension up to the free surface.

[18] A simultaneous analysis of Figures $4 \mathrm{~b}$ and $4 \mathrm{c}$ shows the role of the lutocline in the transport of turbulence inside the tank. The turbulence-sediment interaction occurs principally through the lutocline. It has a measurable effect on the change in $k$ only in highly stratified conditions (runs $3-$ 5). In this situation, the level of turbulent energy measured just above the lutocline is less than ten times smaller than it would have been in clear water. The interface acts as a barrier to the diffusion of turbulence. Moderately stratified conditions exhibit a very different behavior (run 6). The influence of sediment on turbulence diffusion is not measurable and the vertical profile of $k(z)$ looks similar to those obtained in clear water (Matsunaga et al.'s [1999] law). In these cases, the turbulence is not really affected by the presence of the density interface and a significant part of it propagates upward. For runs $7-8$, the condition of saturation as defined in section 3 is not satisfied.

[19] We are not aware of any measurement of turbulent kinetics in CBS layers, and therefore we should comment in more detail on the accuracy of the acoustic Doppler velo- 
cimeter [Gratiot et al., 2000]. The system was also used to measure vertical profiles of turbulent kinetic energy in clear water. Measurements carried out in the course of run 1 and run 2 (without sediments) are presented in Figure $4 \mathrm{a}$ and compared with some of the numerous results published in the literature. Many works have described the diffusion of turbulent kinetic energy by oscillating grid turbulence in homogeneous or in buoyancy stratified fluids. The working fluids usually considered are clear water and/or salt water solutions [Thompson and Turner, 1975; Hopfinger and Toly, 1976; Ura et al., 1987; Nokes, 1988]. Matsunaga et al. [1999] used glycerin additives to achieve variations in the viscosity $\nu$. We observe in Figure 4a that our ADV turbulent kinetic energy measurements in clear water (runs 1-2) fit the $k-\varepsilon$ analytical solution proposed by Matsunaga et al. [1999]:

$$
\frac{k_{c w}}{k_{0}}=\left(\frac{1}{1.82} \frac{z}{z_{0}}+1\right)^{-5},
$$

where $z$ is the vertical elevation from the grid mid plane. Variables $k_{o}$ and $z_{o}=k_{o}^{3 / 2} / \varepsilon_{o}$ are constants that depend on the grid Reynolds number $\left(\operatorname{Re}=F S^{2} / \nu\right)$ :

For $R e<5500$

$$
\begin{gathered}
\frac{k_{o}}{F^{2} S^{2}}=8.1 \times 10^{-3}(S / M)^{1 / 4} \operatorname{Re}^{1 / 2} \\
\frac{\varepsilon_{o}}{F^{3} S^{2}}=8.2 \times 10^{-5}(S / M) R e,
\end{gathered}
$$

For $R e \geq 5500$

$$
\begin{gathered}
\frac{k_{o}}{F^{2} S^{2}}=6 \times 10^{-1}(S / M)^{1 / 4}, \\
\frac{\varepsilon_{o}}{F^{3} S^{2}}=4.5 \times 10^{-1}(S / M) .
\end{gathered}
$$

$F, S$ and $M$ being grid-stirred parameters introduced in section 3. When the distance from the free surface is less than a few $\mathrm{cm}\left(z / z_{o}>4\right)$, our experimental data deviate from Matsunaga et al.'s [1999] law and the turbulent kinetic energy tends to become constant. This difference between experiments and the analytical solution is interpreted as an effect of the free surface. This physical barrier completely stops the upward diffusion of turbulence. The energy is trapped in the upper part of the fluid column before being dissipated by viscous effects. The level of turbulence could also be sustained by the small vibrations of the tank.

[20] For application to runs with sediment, the choice between $(7 a)-(7 b)$ or $(7 c)-(7 d)$ requires an estimate of the fluid viscosity $\nu$. In view of the experimental investigation by van Rijn [1989], we considered that $v$ is not significantly affected by the presence of sediment, except for runs 3 and 4 , carried out with very concentrated fluid mud mixtures (see Table 1). For these runs, the viscosity was taken to be $7 \times 10^{-6} \mathrm{~m}^{2} \mathrm{~s}^{-1}$ and $3 \times 10^{-6} \mathrm{~m}^{2} \mathrm{~s}^{-1}$, respectively.

[21] The main result of Figure $4 \mathrm{~b}$ is the observation that the level of turbulence is not significantly modified inside the CBS layer by the presence of sediments, except when

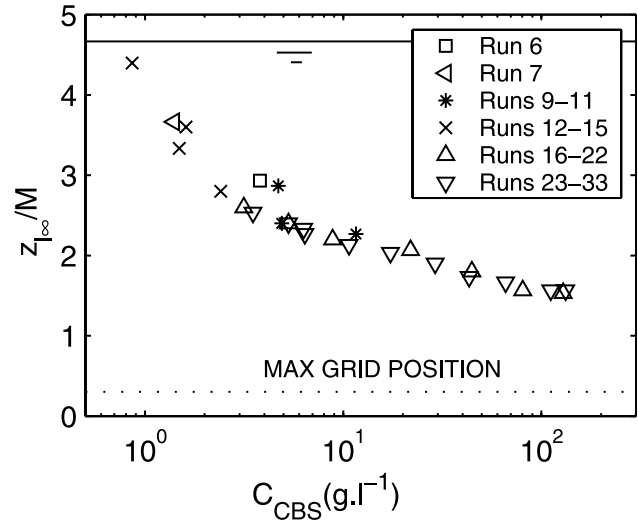

Figure 5. Variation in lutocline position with mean CBS layer concentration. The grid frequency is $F=4 \mathrm{~Hz}$. Symbols and experimental parameters are given in Table 1.

passing across the lutocline. Clear water values presented in Figure 4a satisfactorily estimate the turbulent kinetic energy inside the CBS layer.

\subsection{Variation in CBS Thickness With Sediment Loading}

[22] The dependence of $z_{\ell \infty}$ with $C_{C B S}$ for all runs conducted with a grid frequency of $4 \mathrm{~Hz}$ (runs 6-33 from Table 1) is shown in Figure 5. Equilibrium states obtained from deposition (runs 6-22) or from entrainment (runs 23-33) procedures fit well together. This clearly indicates that the steady state is reached and is furthermore not affected by the transient stage. For SSC less than five grams per liter, the lutocline is naturally pushed closer to the free surface. In this case, visual estimation of $z_{\ell \infty}$ is not easy because the lutocline is subjected to diffusion and largely convoluted, producing a significant scatter in the data. When SSC increases up to $70 \mathrm{~g} \mathrm{~L}^{-1}$, a continuous fall in the lutocline position down to $z_{\ell \infty} / M \approx 1.5$ is observed. For higher SSC, up to $133 \mathrm{~g} \mathrm{~L}^{-1}$, the fall becomes insignificant.

[23] The monotonous fall in the lutocline with sediment loading was previously observed by $E$ and Hopfinger [1987] and later, by Huppert et al. [1995] who conducted the most complete study on steady state suspension layers. Their experiments covered a wide range of particle concentrations ( 2 to $280 \mathrm{~g} \mathrm{~L}^{-1}$ ) and a wide range of grid oscillation frequencies $(0.5$ to $5.2 \mathrm{~Hz})$. The buoyancy effect was due to the injection of noncohesive silicon carbide grit of different sizes having a Stokes equivalent free-fall velocity in the range $\left[3.7 \times 10^{-5}-3.8 \times 10^{-4}\right] \mathrm{m} \mathrm{s}^{-1}$. Assuming that the settling flux is compensated by the grid action defined as $F d^{2}$, where $d$ is a constant depending on the geometrical parameters of the system, Huppert et al. [1995] derived a semiempirical law to estimate the settling flux:

$$
\phi=\frac{\left(F d^{2}\right)^{3}}{G z_{\ell \infty}^{4}},
$$

with $G=g\left(\rho_{s}-\rho_{w}\right) /\left(\rho_{s} \rho_{w}\right)$.

[24] In Huppert et al. [1995] experiments, the monotonous fall of the lutocline with sediment loading is not 
surprising since the increase in concentration is continuously linked to an increase in the particle settling flux in the case of noncohesive particles. A more complex behavior is expected for cohesive sediment mixtures. We indicated in section 2 (Figure 2) that hindering processes appear for SSC values beyond $10-20 \mathrm{~g} \mathrm{~L}^{-1}$ in still water. Hence for higher concentrations, the sediment settling flux may decrease with increasing concentration if the settling velocity decreases sufficiently and consequently, the lutocline should rise. This is not observed in the set of experimental results reported on Figure 5. We argue, as discussed later, that the effective settling flux of cohesive sediments in turbulent conditions diverges significantly from that in quiescent conditions, at least for concentrations higher than $10-20 \mathrm{~g} \mathrm{~L}^{-1}$.

[25] Michallet and Mory [2004] recently derived an analytical expression relating the fluid mud layer thickness to the sediment concentration in the fluid mud layer in the form

$$
z_{\ell \infty} / z_{o} \propto\left(\frac{G w_{s} C_{\mathrm{CBS}} z_{o}}{k_{o}^{3 / 2}}\right)^{-1 / 4}=\left(\operatorname{Rou}_{o} R i_{o}\right)^{-1 / 4} .
$$

The Rouse and Richardson numbers at the level of the grid mid position are defined as

$$
\begin{gathered}
\operatorname{Rou}_{o}=\frac{w_{s}}{\sqrt{k_{o}}} \\
R i_{o}=\frac{G \sqrt{k_{o}} C_{\mathrm{CBS}}}{\varepsilon_{o}},
\end{gathered}
$$

respectively. The relationship is equivalent to (8) but it was obtained for more general conditions. The Rouse and Richardson numbers are bulk parameters of the experiment which compare the properties of the suspension with the grid oscillation parameters. By comparing the numerical results of a $k-\varepsilon$ model and the experimental results of Huppert et al. [1995], Michallet and Mory [2004] obtained a best fit of (9a) in the form

$$
z_{\ell \infty} / z_{o}=0.6\left(\operatorname{Rou}_{o} R i_{o}\right)^{-1 / 4}=0.6\left(\frac{G w_{s} C_{\mathrm{CBS}} z_{o}}{k_{o}^{3 / 2}}\right)^{-1 / 4}
$$

Equation (10) could be directly compared with the results in Figure 5 if the settling velocity were known.

\subsection{Interpretation of the Experimental Results}

[26] The basic feature that governs the equilibrium state in grid-stirred experiments is the balance between the upward turbulent flux and the downward sediment settling flux. For a given input of energy two situations having the same concentration and the same settling velocity are expected to locate the lutocline at the same position in the equilibrium state. However, equation (10) tells more because the concentration and the settling velocity appear in (10) through the settling flux $\phi=w_{s} C_{\mathrm{CBS}}$. In other words, for fixed grid parameters (F, S, M, $m$ and $h_{g}$, see section 3 ), the lutocline position depends only on the sediment settling

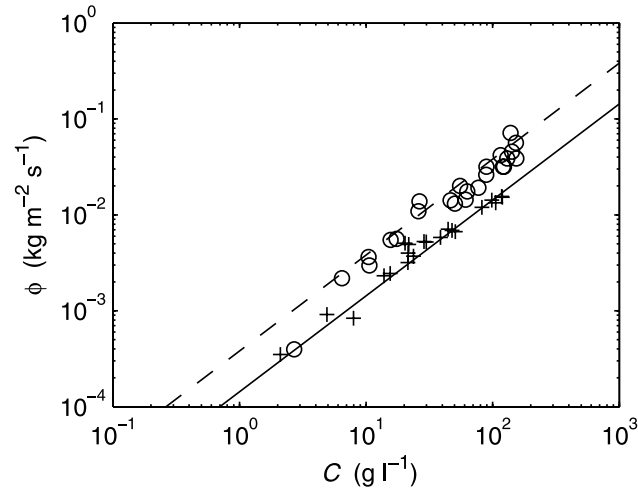

Figure 6. Variation in settling flux versus concentration for noncohesive particle suspensions in Huppert et al.'s [1995] experiments $\left(\rho_{s}=3.217 \mathrm{~kg} \mathrm{~L}^{-1}\right) . D_{50}=17.6 \mu \mathrm{m}$ : experimental data (circles) and settling flux computed with the Stokes free-fall velocity (dashed line). $D_{50}=10.8 \mu \mathrm{m}$ : experimental data (plusses) and settling flux computed with the Stokes free-fall velocity (solid line).

flux. Equation (10) can be rewritten to estimate the settling flux in terms of grid turbulence parameters and of the position of the lutocline. We obtain

$$
\phi=w_{s} C_{\mathrm{CBS}}=\left(\frac{0.6 z_{0}}{z_{\ell \infty}}\right)^{4} \frac{k_{o}^{3 / 2}}{G z_{0}} .
$$

An indirect estimate of the settling flux is therefore obtained for each run from the position of the lutocline. Since the concentration in the CBS layer is known, the settling flux in the turbulent mixed CBS layer can then be compared with the estimates of the settling flux deduced from settling velocity measurements. A comparison of the two estimates of the settling flux is first shown in Figure 6 for the experimental results of Huppert et al. [1995]. In this figure estimates of the settling flux determined using (11) with the experimental data of the lutoline position are shown as circles and plus signs. Two different classes of particles are considered. Particles employed by Huppert et al. [1995] are noncohesive. For the size of particles considered, the settling velocity of particles can be estimated using the Stokes free-fall model. The settling flux for the two classes of particles estimated from the Stokes free-fall velocity is also superimposed in Figure 6 as solid lines. We notice the good match of the settling flux determined from both ways. The settling flux is therefore satisfactorily determined from the mixing tank experiments using the data for the interface position. It furthermore indicates that the settling flux is not affected by the presence of turbulence for the particles and for the range of parameters considered in Huppert et al.'s [1995] experiments, since the Stokes law for particles settling in quiescent fluid fits data for estimating the settling flux.

[27] A similar comparison is shown in Figure 7 for the experiments with fluid mud carried out in the course of the present study. The settling flux was first computed using (11) and the data on the lutocline position of Table 1. The comparison is made with the settling flux determined from settling experiments in quiescent fluid presented in section 2 . 


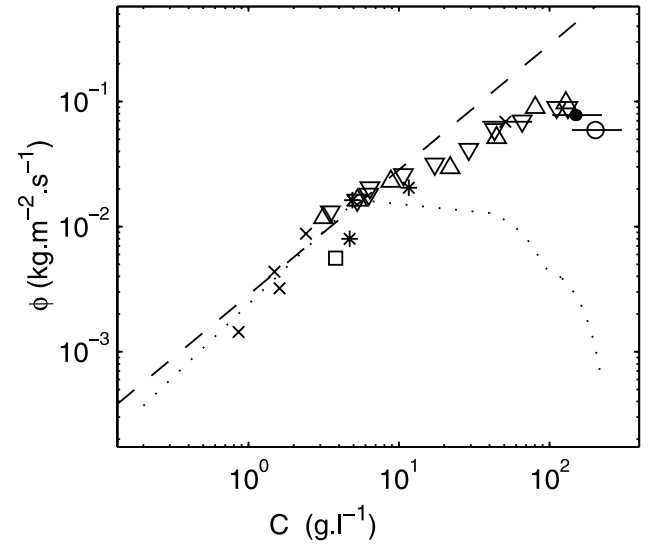

Figure 7. Variation in the settling flux with concentration for cohesive particle suspensions. Symbols and experimental conditions of fluid mud experiments are given in Table 1. The dotted line is the settling flux in quiescent fluid (Figure 2). The dashed line is the settling flux computed using the Stokes free-fall velocity (Figure 2).

The dotted line in Figure 2a is reproduced in Figure 7 and the settling flux using the Stokes free-fall velocity is additionally shown as the dashed line. Several conclusions emerge. In the low SSC values (up to $10 \mathrm{~g} \mathrm{~L}^{-1}$ ), we observe a good match of the different estimates. The settling flux is well determined from settling experiments in quiescent fluid. The presence of turbulence does not modify the settling flux. In contrast, when the SSC of the cohesive suspension exceeds $10 \mathrm{~g} \mathrm{~L}^{-1}$, the settling flux in turbulent flow (symbols) is much higher than the settling flux measured in quiescent conditions for the same concentration, as shown by the logarithmic scale of the figure. The difference can reach as much as two orders of magnitude for the highest concentrations. The settling flux in turbulent flow increases with increasing sediment concentration with a power law of the form $\phi=\beta C^{0.75}$. Because the power law exponent is less than unity, the settling velocity decreases with increasing SSC. A hindered effect thus still exists but is considerably reduced as compared to that in quiescent conditions. Because the turbulence conditions achieved in Huppert et al.'s [1995] experiments were not much different from those achieved in ours, and since the estimates of the free-fall settling velocity satisfactorily reflect the settling flux for the experimental data of Huppert et al. [1995], we suggest that hindering effects in the range $[10-130] \mathrm{g} \mathrm{L}^{-1}$ are due to a modification in individual floc properties, possibly related to floc breakage by collision. A few data for very high concentrations (above $130 \mathrm{~g} \mathrm{~L}^{-1}$ ) indicate a decrease in the sediment settling flux. This change is rather abrupt and is probably due to a modification in the CBS properties, as it is not observed with the noncohesive suspensions. By extrapolating a flocculation model to high SSC, Winterwerp [2002] established a relation between the gelling concentration and the dissipation parameter that characterizes shear in coastal and estuarine sediment transport processes. An application of Winterwerp's [2002] model predicts the gelling concentration for our mud $\left(C_{\mathrm{gel}} \approx 95 \mathrm{~g} \mathrm{~L}^{-1}\right.$ in still water) to be of the order of $120-160 \mathrm{~g} \mathrm{~L}^{-1}$ in the turbulent conditions of the grid- stirred experiments. This corresponds to the value for which the sediment settling flux starts to decrease (in Figure 7). Hence the gelling point could correspond to the condition leading to an increase in hindering effects in turbulent flows.

\section{Conclusions}

[28] We have examined the influence of turbulence on changes in the settling flux of cohesive particle suspensions in a purely diffusive turbulent flow produced by grid stirring. By measuring vertical profiles of the turbulent kinetic energy $k(z)$ and of the concentration $C(z)$ it was possible to show that turbulence distribution in the CBS layer is not significantly modified as compared with clear water experiments, except in the vicinity of lutoclines, where the turbulence-sediment interaction takes place. A wide range of concentrations have been considered, covering all settling regimes observed in natural conditions, from free floc settling to hindered sedimentation and consolidation.

[29] The variation in CBS thickness with sediment concentration in the CBS layer was determined from experiments. Using recent analytical developments it is shown that the settling flux in CBS layers can be determined from grid oscillation parameters and from the position of the lutocline. This property was used to investigate the effect of turbulence on the settling flux of a cohesive sediment mixture. Hindering effects observed under quiescent conditions when the concentration exceeds approximately $10 \mathrm{~g} \mathrm{~L}^{-1}$ are considerably reduced in highly turbulent conditions. The absolute decrease in sediment settling flux occurs only with concentrations higher than $130 \mathrm{~g} \mathrm{~L}^{-1}$, presumably beyond the gelling point.

[30] Variation in the settling flux of cohesive sediment with concentration has been established for a long time but, in the light of this work, we demonstrate that under a specific hydrodynamic forcing the influence of isotropic homogeneous turbulence on settling flux can override concentration effects. In highly turbulent conditions and when the concentration exceeds about $60 \mathrm{~g} \mathrm{~L}^{-1}$, sediment settling is one to two orders of magnitude greater than predicted in quiescent fluid. This may have important consequences, in particular for the dynamics of concentrated benthic suspension layers and for the modeling of cohesive sediment transport. Further investigations are needed in the context of naturally produced turbulence, such as shear flows and biologically active sediments.

[31] Acknowledgments. This work was mainly funded by the European project COSINUS within the framework of the MAST-3 program, contract MAS3-CT97-0082. We are grateful to E. Hopfinger, who made the grid tank facility available, to J.-M. Barnoud for his continuous technical assistance, and to D. Hurther and K. Guizien for constructive criticisms. Many thanks to our COSINUS partners, especially A. Manning, for their scientific support. Finally, P. J. Kirby and two anonymous reviewers are gratefully acknowledged for their comments on the manuscript.

\section{References}

de Croutte, E., J. M. Gallissaires, and L. Hamm (1996), Flume measurements of mud processes over a flat bottom under steady and unsteady currents, Rep. R3, Sogreah Consult., Grenoble, France.

Dyer, K. R., and A. J. Manning (1999), Observation of the size, settling velocity and effective density of flocs, and their fractal dimensions, J. Sea Res., 41(1-2), 87-95.

Dyer, K. R., et al. (1996), A comparison of in situ techniques for estuarine floc settling velocity measurement, J. Sea Res., 36(1-2), 15-29. 
E, X., and E. Hopfinger (1987), Stratification by solid particle suspension, in Proceedings of the Third International Symposium on Stratified Flows, edited by E. J. List and G. H. Jirka, pp. 488-495, Am. Soc. of Civ. Eng., New York.

Fennessy, M. J., K. R. Dyer, and D. A. Huntley (1994), INSSEV: An instrument to measure the size and settling velocity of flocs in situ, Mar. Geol., 117, 107-117.

Fugate, D. C., and C. T. Friedrichs (2002), Determining concentration and fall velocity of estuarine particle populations using ADV, OBS and LISST, Cont. Shelf Res., 22(11-13), 1867-1886.

Gratiot, N. (2000), Etude expérimentale de la formation des couches de crèmes de vases turbulentes, Ph.D. thesis, Univ. de Grenoble, Grenoble, France.

Gratiot, N., and A. J. Manning (2004), An experimental investigation of floc characteristics in a diffusive turbulent flow, J. Coastal Res., SI41, $105-113$.

Gratiot, N., M. Mory, and D. Auchère (2000), An acoustic Doppler velocimeter (ADV) for the characterisation of turbulence in concentrated fluid mud, Cont. Shelf Res., 20, 1551-1567.

Hopfinger, E. J., and J.-A. Toly (1976), Spatially decaying turbulence and its relation to mixing across density interfaces, J. Fluid Mech., 78, $155-$ 175.

Huppert, H. E., J. S. Turner, and M. A. Hallworth (1995), Sedimentation and entrainment in dense layers of suspended particles stirred by an oscillating grid, J. Fluid Mech., 289, 263-293.

Kineke, G. C., R. W. Sternberg, J. H. Trowbridge, and W. R. Geyer (1996), Fluid mud processes on the Amazon continental shelf, Cont. Shelf Res., 16(5-6), 667-696.

Kynch, G. J. (1952), A theory of sedimentation, Trans. Faraday Soc., 48, $166-176$.

Manning, A. J., and K. R. Dyer (1999), A laboratory examination of floc characteristics with regard to turbulent shearing, Mar. Geol., 160, 147170 .

Matsunaga, N., Y. Sugihara, T. Komatsu, and A. Masuda (1999), Quantitative properties of oscillating-grid turbulence in a homogeneous fluid, Fluid Dyn. Res., 25, 147-165.

McCool, W. W., and J. D. Parsons (2004), Sedimentation from buoyant fine-grained suspensions, Cont. Shelf Res., 24, 1129-1142.

Mehta, A. J. (1989), On estuarine cohesive sediment suspension behavior, J. Geophys. Res., 94(C10), 14,303-14,314.

Michallet, H., and M. Mory (2004), Modeling sediment suspensions in oscillating grid turbulence, Fluid Dyn. Res., 35, 87-106.

Migniot, C. (1968), Etude des propriétés physiques de différents sédiments très fins et de leur comportement sous des actions hydrodynamiques, Houille Blanche, 7, 591-620.

Milligan, T. G., and P. S. Hill (1998), A laboratory assessment of the relative importance of turbulence, particle composition, and concentration in limiting maximal floc size and settling behaviour, J. Sea Res., 39, $227-241$.

Mory, M., N. Gratiot, A. J. Manning, and H. Michallet (2002), CBS layers in a diffusive turbulence grid oscillation experiment, in Fine Sedimen Dynamics in the Marine Environment, edited by J. C. Winterwerp, and C. Kranenburg, pp. 139-154, Elsevier, New York.
Nokes, R. I. (1988), On the entrainment rate across a density interface, J. Fluid Mech., 188, 185-204.

Ross, M. A. (1988), Vertical structure of estuarine fine sediment suspensions, Ph.D. thesis, Coastal and Oceanogr. Eng. Dep., Univ. of Fla., Gainesville.

Ross, M. A., and A. J. Mehta (1989), On the mechanics of lutoclines and fluid mud, J. Coastal Res., 5, 51-62.

Thompson, S. M., and J. Turner (1975), Mixing across an interface due to turbulence generated by an oscillating grid, J. Fluid Mech., 67, 349368.

Thorn, M. F. C. (1982), Physical processes of siltation in tidal channels, in Hydraulic Modelling in Maritime Engineering: Proceedings of the Conference/Organized by the Institution of Civil Engineers, Held in London on 13-14 October 1981, pp. 47-55, Thomas Telford, London.

Toorman, E. (1992), Modelling of fluid mud flow and consolidation, Ph.D. thesis, Hydraul. Lab., Katholieke Univ. Leuven, Leuven, Belgium.

Toorman, E. (1999), Sedimentation and self-weight consolidation: Constitutive equations and numerical modelling, Geotechnique, 49, 709-726.

Ura, M., T. Komatsu, and N. Matsunaga (1987), Entrainment due to oscillating-grid turbulence in two-layered fluid, in Turbulence Measurements and Flow Modeling, edited by C. J. Chen, L.-D. Chen, and F. M. Holly Jr., pp. 109-118, Taylor and Francis, Philadelphia, Pa.

van Leussen, W. (1986), Laboratory experiments on the settling velocity of mud flocs, in Proceedings of the Third International Symposium on River Sedimentation: General Theme, Estuarine and Coastal Sedimentation, River Sediment, vol. 3, edited by S. Y. Wang, H. W. Shen, and L. Z. Ding, pp. 1803-1812, Sch. of Eng., Univ. of Miss., Oxford.

van Leussen, W. (1994), Estuarine macroflocs and their role in fine-grained sediment transport, Ph.D. thesis, 484 pp., Univ. of Utrecht, Utrecht, Netherlands.

van Rijn, L. C. (1989), Sediment transport by currents and waves, Rep. H 461, WL|Delft Hydraul., Delft, Netherlands.

Winterwerp, J. C. (2002), On the flocculation and settling velocity of estuarine mud, Cont. Shelf Res., 22, 1339-1360.

Wolanski, E., J. Chappell, P. Ridd, and R. Vertessy (1988), Fluidization of mud in estuaries, J. Geophys. Res., 93(C3), 2351-2361.

Wolanski, E., T. Asaeda, and J. Imberger (1989), Mixing across a lutocline, Limnol. Oceanogr., 34(5), 931-938.

Wolanski, E., R. J. Gibbs, Y. Mazda, A. Mehta, and B. King (1992), The role of turbulence in the settling of mud flocs, J. Coastal Res., 8(1), 3546.

N. Gratiot, Laboratoire d'étude des Transferts en Hydrologie et Environnement, IRD, UJF, INPG, CNRS, BP 53, F-38041 Grenoble Cedex 09, France. (nicolas.gratiot@hmg.inpg.fr)

H. Michallet, Laboratoire des Ecoulements Géophysiques et Industriels, Université Joseph Fourier, INPG, CNRS, BP53, F-38041 Grenoble Cedex 9, France. (herve.michallet@hmg.inpg.fr)

M. Mory, Ecole Nationale Supérieure en Génie des Technologies Industrielles, Université de Pau et des Pays de l'Adour, rue Jules Ferry, BP 7511, F-64075 Pau, France. (mathieu.mory@univ-pau.fr) 